\title{
Assessment of role of concrete factories in particulate matter emissions, 2015-2016, using the AQI index and zoning by GIS software (Case study: Nasr Kashan Concrete Factory)
}

\author{
Shahnaz Kushkbaghi ${ }^{1}$, Mohammad Hassan Ehrampoush ${ }^{2 *}$, Seyed Abolghsem Mirhosseinidehabadi ${ }^{3}$ \\ ${ }^{1} \mathrm{MSc}$ of Environmental Health Engineering, Department of Environment, School of Agriculture and Natural Resource, Yazd Branch, \\ Islamic Azad University, Yazd, Iran \\ ${ }^{2}$ Professor of Environmental Health Engineering, Research Center for Environmental Health Technology, Department of Environmental \\ Health, School of Health, Shahid Sadoghi University of Medical Sciences, Yazd, Iran \\ ${ }^{3}$ Associate Professor, Department of Environment, School of Agriculture and Natural Resource, Yazd Branch, Islamic Azad University, \\ Yazd, Iran
}

\begin{abstract}
Background: Reducing the effects of climate change and air pollution is a global priority at present. To formulate effective policies for achieving such a reduction requires a good understanding of the underlying phenomena. This study assessed the role of Nasr Kashan Factory in the emissions of particulate matter (PM).

Methods: In this cross-sectional study, PM concentrations at 9 stations inside and around the Nasr Kashan Concrete Factory were determined at the unit's active and inactive times. The air quality index (AQI) was obtained and data was entered into ArcGIS 10.2 to obtain a zoning map of PM dispersion. Results: The results showed that all AQI peaks were within the very healthy or the healthy range at the Factory's inactive times. When the factory was working, the AQIs ranged from 24.1 to $634 \mu \mathrm{g} / \mathrm{m}^{3}$, which falls into the good and very hazardous categories. These results were dependent upon distance from the factory and were further affected by other produced factors of PM10.

Conclusion: The results of this paper showed that average PM emissions at the Nasr Kashan Concrete Factory were much lower during inactive times than during times of activity. Therefore, the Nasr Kashan Concrete Factory plays an important role in the emission of PM and in air pollution in the studied area. PM concentrations were higher near and inside the studied factory, and the AQI was in the hazardous category.

Keywords: Air pollution, Particulate matter 10, Software GIS, Air quality index, Kashan

Citation: Kushkbaghi S, Ehrampoush MH, Mirhosseinidehabadi SA. Assessment of role of concrete factories in particulate matter emissions, 2015-2016, using the AQI index and zoning by GIS software (Case study: Nasr Kashan Concrete Factory). Environmental Health Engineering and Management Journal 2017; 4(3): 149-155. doi: 10.15171/EHEM.2017.21.
\end{abstract}

Article History:

Received: 19 September 2016 Accepted: 15 April 2017

ePublished: 2 May 2017

\section{Introduction}

At present, reducing the effects of climate change and air pollution is a global priority. Therefore, devising effective policies is a challenge that requires a good understanding of the underlying phenomena of climate change and air pollution (1). Air pollution due to industrialization and urbanization is one of the major environmental issues of the current century, especially in developing countries. Air pollution is a mixture of different atmospheric pollutants such as particulate matter (PM), nitrogen dioxide (NO2), carbon monoxide, ozone, sulfur dioxide, etc. In recent decades, researchers have investigated short-term and long-term exposure to air pollutants and the outcome of such exposure on human health (2).
The chemical and physical properties of PM are of great importance in the area of environmental and health effects (3). Two groups of particles are particularly important: particles smaller than 10 microns (PM10) that enter the lower parts of the lung, and particles smaller than 2.5 microns (PM2.5) that are deposited in the alveoli and also enter the blood flow. Numerous studies conducted on the human body have shown that there is a significant relationship between upper and lower lung infections and increased concentrations of PM and sulfur dioxide in the air. On average, $35 \mu \mathrm{g} / \mathrm{m}^{3}$ of PM10 cause 55 of each 100000 deaths. The size of these particles is directly related to their ability to cause harm to human health. Particles with a diameter of 10 microns or less present a higher risk for 
health (3).

To report air pollution through the mass media, indicators are used. First, the indicator of air pollution (PSI1) was used to report the severity and effects of air pollution. In 1999, the US Environmental Protection Agency (EPA) introduced the air quality index (AQI), which emphasized smaller particles (PM2.5). The AQI shows the effects of polluted air on health. This indicator is calculated using a formula and the concentration of pollutants (carbon monoxide, ozone in the Earth's surface, PM, sulfur dioxide, and NO2). After calculating, the range 0-500 is divided into different zones and each zone shows the amount of air pollution (4).

In general, the AQI of a region enables people to determine the qualitative status of the weather as it regards health and hygiene. In addition, managers and officials use the AQI to prescribe precautions required for each of the items of air quality.

The most important sources of PM in the air of large cities include particles worn from vehicle brake pads, asphalt streets, and metal compounds from industrial processes such as lead, cadmium, sulfates, pollen, microorganisms, particles, and soot (5).

An important and effective measure for finding suitable methods for removing the risks and damages of air particles is to determine the actual amount of particulate matter emissions, compare the air quality with standards, and give simple notification to the public when air quality and pollution go beyond standard levels $(6,7)$.

This study assessed the particulate matter emissions of Nasr Kashan Concrete Factory using the AQI and zoning with GIS software.

Studies in other cities have shown that high $\mathrm{PM}_{10}$ levels affect increases in morbidity and mortality rates (8). Studies have indicated that common concentrations of $\mathrm{PM}_{10}$ adversely impact health in many urban areas. These impacts include aggravation of existing respiratory disease and decline in lung function (9).

The study by Hosseini et al on the city of Sanandaj showed that the average $\mathrm{PM}_{10}$ concentration was $160.63 \mu \mathrm{g} / \mathrm{m}$, and the lowest and highest concentrations of particulate matters occurred in the months of May and June, respectively. Average concentrations of $\mathrm{PM}_{10}$ on non-dusty days was $96.88(\mu \mathrm{g} / \mathrm{m})$, which is 4.8 times higher than on dusty days. On dusty days, the dominant elements in $\mathrm{PM}_{10}$ were $\mathrm{Na}, \mathrm{Ca}, \mathrm{Mg}, \mathrm{Al}$, and Fe contributing to $95.72 \%$ of total measured metals. Concentrations of $\mathrm{PM}_{10}$ during dusty days were considerably higher than that during non-dusty days. The WHO ranked Sanandaj as the third most polluted city in the world in terms of $\mathrm{PM}_{10}(10)$. The WHO ranked Sanandaj as the third most polluted city in the world in terms of $\mathrm{PM}_{10}(11)$.

\section{Materials and Methods}

Study area

The Nasr Kashan Concrete plant is located in northeastern
Kashan at the intersection of Nosh Abad and Mohammad Abad roads. The latitude and longitude of this area is $51^{\circ}$ $26^{\prime} 30^{\prime \prime}$ East and $34^{\circ} 1^{\prime} 38^{\prime \prime}$ North, and its altitude is 920 meters above sea level (Figure 1).

There are seven truck mixers and three concrete transfer pump machines in this plant. The daily production rate is about 480 tons of concrete and includes all two sand tissues, gravel and pebble sand for different uses. In addition, there are 5 cement silos at this plant. The plant has an area of about $2300 \mathrm{~m}^{2}$, and the height of the wall is about $230 \mathrm{~cm}$.

\section{Sampling}

To measure the amount of pollution created by the plant in terms of PM in the air, 9 stations in areas surrounding the plant were identified. Because of the heterogeneous nature of the environment around the plant (vacant lands, other factories, gardens, etc), sampling was done mainly on vacant lands along roadways; pollution caused by the plant and noise pollution caused by traffic on the roads were also taken into consideration. Figure 2 and Table 1 show the position of sampling stations.

Sampling was performed with 12 reps at each station, based on the National Institute for Occupational Safety and Health (protocol 0500) (9). This method was used to determine the concentration of suspended particles that

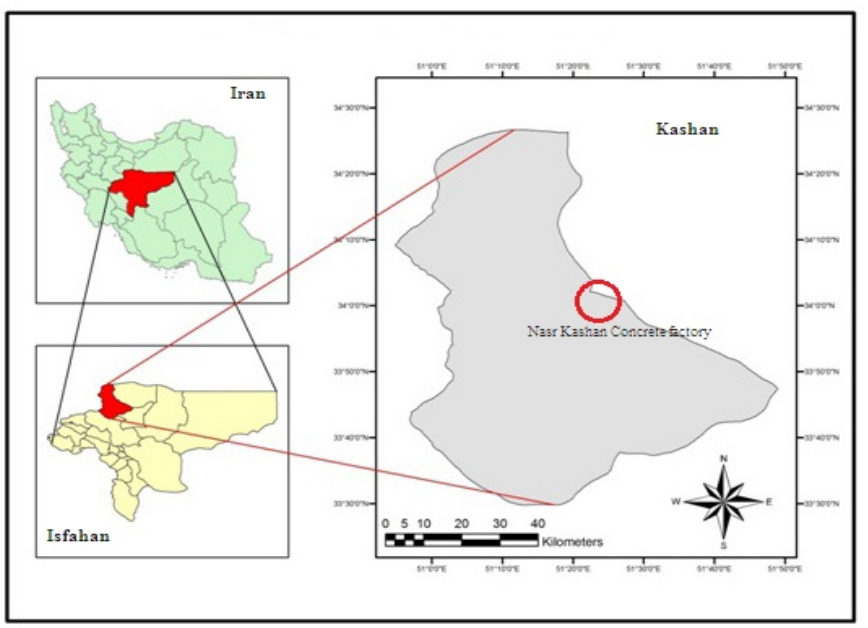

Figure 1. Location of Kashan city and Nasr Kashan Concrete factory.

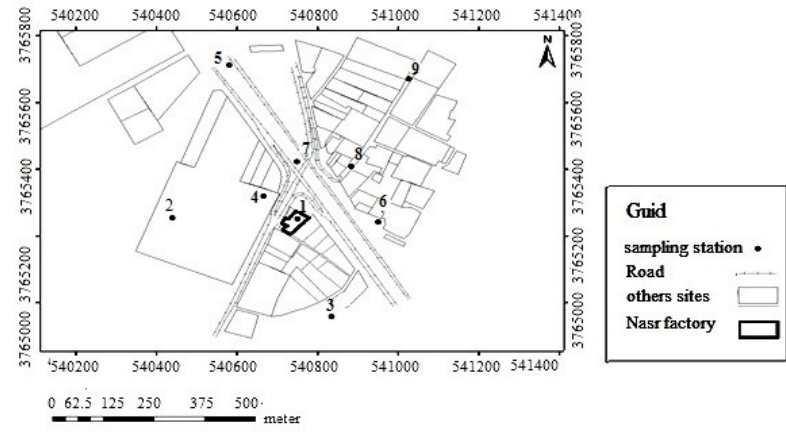

Figure 2. Sampling stations in studied area. 
Table 1. Location of sampling stations in studied area

\begin{tabular}{lcccl}
\hline Station & \multicolumn{2}{c}{ Coordinate $(\mathbf{m})$} & Distance of the factory $(\mathbf{m})$ & Location \\
\hline 1 & $540750 / 5$ & $3765252 / 55$ & 0 & Inside of the studied factory \\
2 & $540439 / 6$ & $3765255 / 57$ & 310.88 & Empty land in the West of the \\
3 & $540835 / 7$ & $3764960 / 03$ & 304.68 & Empty area out of structures in the south of Nasr factory \\
4 & $540667 / 1$ & $3765320 / 02$ & 107.3 & Empty land in the West of the studied factory \\
5 & $540581 / 5$ & $3765713 / 03$ & 490.5 & Between Mohammad Abad road in north of Nasr factory \\
6 & $540951 / 1$ & $3765242 / 16$ & 200.8 & East Road of Nasr factory on the edge of the road and private places \\
7 & $540749 / 2$ & $3765423 / 58$ & 171 & Crossing the road of Noushabad and Mohammad Abad in the north of Nasr \\
8 & $540883 / 7$ & $3765408 / 76$ & 205.3 & factory \\
9 & 541028 & $3765670 / 6$ & 501.8 & Inside of sub alley in the North East of Nasr factory \\
\hline
\end{tabular}

affect people working in the plant. However, because the weather outside the factory was calm and without much air flow, the same method was used to measure pollutants. PVC filters with a diameter of $37 \mathrm{~mm}$ and $5 \mathrm{~mm}$ mesh and an SKC pump with an input capacity of $2 \mathrm{~L} / \mathrm{m}$ were used in sampling. About $75 \mathrm{~L}$ of air was passed per filter station. Before sampling, filters were coded under laboratory conditions and then placed in special cassettes in sampling place was connected to the pump. After sampling, the cassettes were transferred directly to the laboratory and weighed with weighing scales (accurate to the milligram). Since the idle time in the factory was like the empty sampling time (Blank), the weight difference created in the filter was considered as the weight of PM. The concentration of particles in units of milligrams per cubic meter was obtained using the following equation:

$C=\frac{\left(W_{2}-W_{1}\right)}{V} \times 10^{3}$

where $W 1$ and $W 2$ are weights of the filter before and after sampling (unit $=\mathrm{mg}$ ), and $V$ is the volume of air $(75 \mathrm{~mL}$ ).

Air quality index

Since the filters have 5-micron pores, the pollutant was PM10, the main pollution caused by factories producing materials.

The AQI was calculated for ground level ozone, particle pollution, carbon monoxide, and sulfur dioxide (the four major air pollutants regulated by the Clean Air Act). The EPA has established national air quality standards for each of these pollutants to protect public health $(9,10)$. The $\mathrm{AQI}$ is divided into six levels of health concerns shown in Table 2.

Equation 2 is used by the EPA to calculate the AQI in terms of PM10 pollution intensity:

$$
I=\frac{I_{\text {high }}-I_{\text {low }}}{C_{\text {high }}-C_{\text {low }}}\left(C+C_{\text {low }}\right)+I_{\text {low }}
$$

Where $\mathrm{I}_{\text {high }}$ and $\mathrm{I}_{\text {low }}$ are the upper and lower air quality indices for air quality, $\mathrm{C}_{\text {high }}$ and $\mathrm{C}_{\text {low }}$ are the upper and lower limit emissions (PM10) in the group of air quality, and $\mathrm{C}$ is pollutant concentration (11).

After determining the amount of pollution and the status of air quality, an air quality zoning map was generated using ArcGIS 10.2 software, and the measurements were taken at times of activity and inactivity at the factory.

\section{Results}

The average, maximum, and minimum PM concentrations and the zoning map of the PM concentrations taken from Nasr factory at both active and inactive times in the studied area are illustrated in Table 3 and Figures 3-5. Figures 6 and 7 show the zoning maps of the PM concentrations $\left(\mu \mathrm{g} / \mathrm{m}^{3}\right)$ in the area.

Table 2. AQI and Health Implications $(9,10)$

\begin{tabular}{|c|c|c|}
\hline AQI & Level of air pollution & Implications of health \\
\hline $0-50$ & Excellent & No health implications. \\
\hline $51-100$ & Good & Few hypersensitive individuals should reduce outdoor exercise. \\
\hline $101-150$ & Lightly Polluted & $\begin{array}{l}\text { Slight irritations may occur, individuals with breathing or heart problems should reduce } \\
\text { outdoor exercise. }\end{array}$ \\
\hline $151-200$ & $\begin{array}{l}\text { Moderately Polluted } \\
\text { (Unhealthy) }\end{array}$ & $\begin{array}{l}\text { Slight irritations may occur, individuals with breathing or heart problems should reduce } \\
\text { outdoor exercise. }\end{array}$ \\
\hline $201-300$ & $\begin{array}{l}\text { Heavily Polluted } \\
\text { (Very Unhealthy) }\end{array}$ & $\begin{array}{l}\text { Healthy people will be noticeably affected. People with breathing or heart problems will } \\
\text { experience reduced endurance in activities. These individuals and the elderly should remain } \\
\text { indoors and restrict activities. }\end{array}$ \\
\hline $300+$ & $\begin{array}{l}\text { Severely Polluted } \\
\text { (Hazardous) }\end{array}$ & $\begin{array}{l}\text { Healthy people will experience reduced endurance in activities. There may be strong irritations } \\
\text { and symptoms and other illnesses may be triggered. The elderly and the sick should remain } \\
\text { indoors and avoid exercise. Healthy individuals should avoid outdoor activities. }\end{array}$ \\
\hline
\end{tabular}




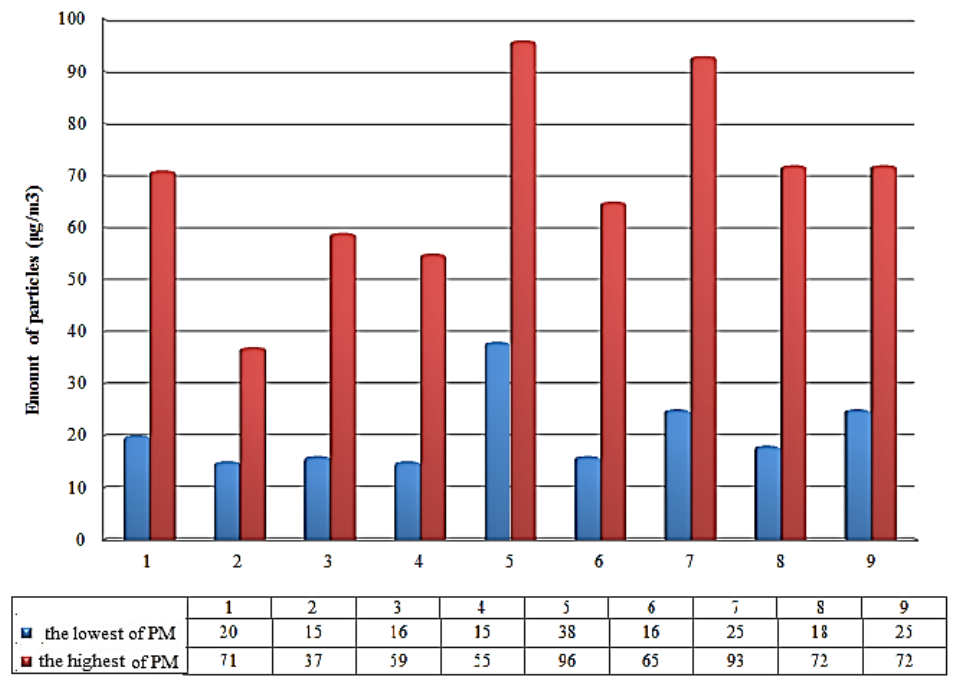

Figure 3. Maximum and minimum particulate matter concentrations at the time of inactivity of the factory in the studied area $\left(\mu \mathrm{g} / \mathrm{m}^{3}\right)$.

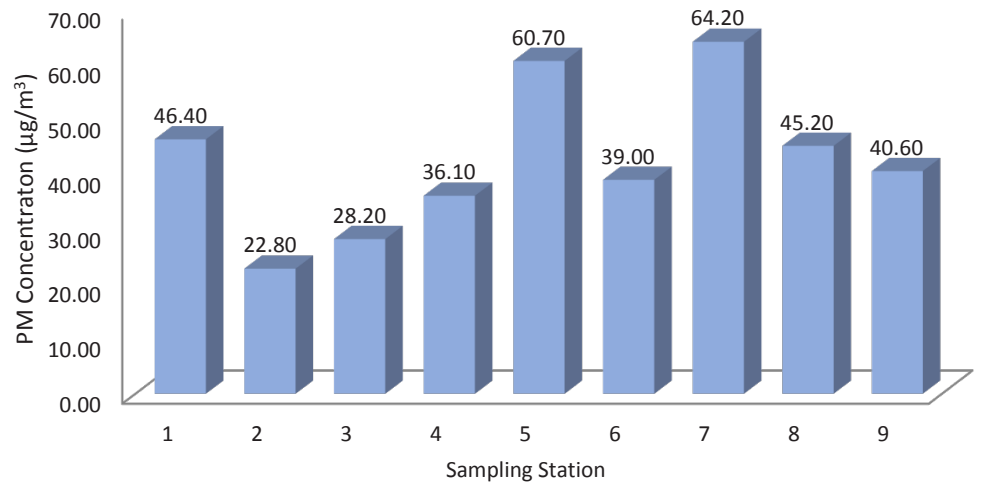

Figure 4. Mean concentrations of PM $\left(\mu \mathrm{g} / \mathrm{m}^{3}\right)$ at the time of inactivity of factory in the studied area.

The results showed that during inactive times, the PM air pollution around the factory is low. It became clear that the two stations on the periphery of the factory (Stations 5 and 7) had the highest amounts of PM, but levels were at a healthy level. The remaining stations were also low. Measurements showed that contamination was minimal in places where the land area was small and surrounded by walls.

Table 3 shows the standard deviation (SD) of PM at active and inactive times of the Nasr Kashan Concrete factory. When the factory was active, the PM concentrations showed that pollution was highest at $738 \mu \mathrm{g} / \mathrm{m}^{3}$ in Station 1 inside the factory and lowest at $26 \mu \mathrm{g} / \mathrm{m}^{3}$ in Station 2. Moreover, there were significant increases in PM concentration at Stations 4, 6, and 8 (Table 1). PM dispersion measurements showed that significant pollution was created inside the studied factory and reached a distance of 100 to $200 \mathrm{~m}$ around it.

The results showed that the average amount of PM at the time of inactivity of Nasr factory was lower than the value recommended by the EPA $\left(150 \mu \mathrm{g} / \mathrm{m}^{3}\right)$ and WHO guidelines $\left(50 \mu \mathrm{g} / \mathrm{m}^{3}\right)$, except at stations 5 and 7; however, at the active times of the Nasr factory, the average PM concentration was higher than the value recommended by WHO guidelines, except at stations 9,5 , and 2 , and lower than the EPA standard at all stations except Stations 4 and 2.

PM zoning maps for active times of the factory showed that the factory causes significant pollution, such that the PM10 concentration inside the factory was more than 500 $\mu \mathrm{g} / \mathrm{m}^{3}$. As distance from the factory increased, air quality improved; PM concentrations were balanced at a distance of about $200 \mathrm{~m}$ from the factory (Figure 6).

\section{Air quality index}

The average, maximum, and minimum estimated AQIs taken from the Nasr factory at active and inactive times are compared in Table 4, and zoning maps for the AQI of PM are shown in Figures 8 and 9.

The calculated AQI at the time of inactivity showed that when the factory was inactive, the lowest AQIs (less than $30 \mu \mathrm{g} / \mathrm{m}^{3}$ ) were estimated at Stations 2 and 3. Zoning maps 
Table 3. Standard deviation (SD) of PM at active and inactive times of Nasr factory

\begin{tabular}{lcc}
\hline Station & SD of data at time activity & SD of data at time inactivity \\
\hline 1 & 119.49 & 14.42 \\
2 & 8.85 & 6.78 \\
3 & 20.68 & 13.11 \\
4 & 73.59 & 13.01 \\
5 & 11.70 & 14.85 \\
6 & 57.29 & 16.67 \\
7 & 45.66 & 20.88 \\
8 & 75.79 & 19.00 \\
9 & 14.52 & 13.54 \\
\hline
\end{tabular}

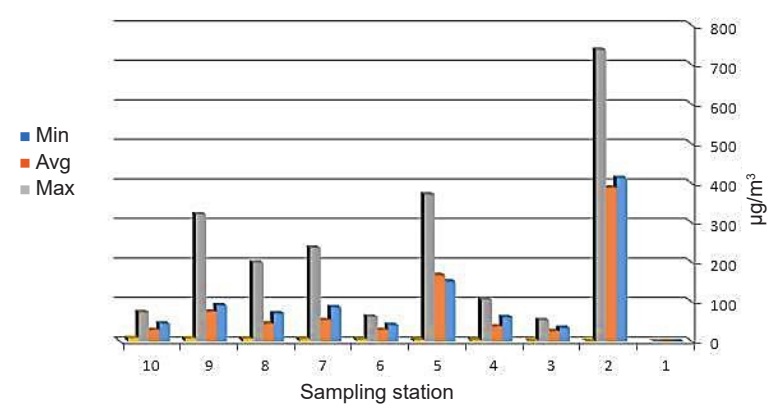

Figure 5. Concentration of particulate matter $\left(\mu \mathrm{g} / \mathrm{m}^{3}\right)$ at the time of activity in the studied area.
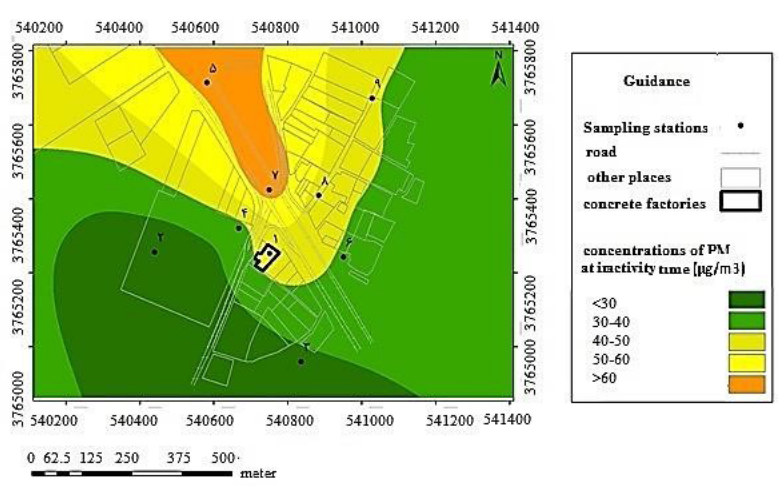

Figure 6. Zoning map of particulate matter concentrations $\left(\mu \mathrm{g} / \mathrm{m}^{3}\right)$ at the time of inactivity of the factory in the studied area.
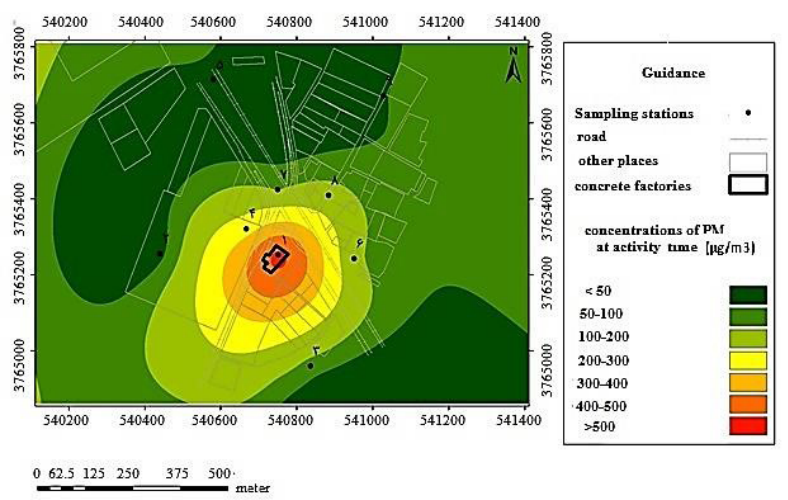

Figure 7. Zoning map of particulate matter concentrations $(\mu \mathrm{g} /$ $\mathrm{m}^{3}$ ) at the time of activity of Nasr Kashan Concrete factory in the studied area. at inactive factory times showed the highest amounts of pollution were found at Stations 5 and 7; the weather was reasonably clean and the AQI was in the range of very healthy (0-50) to healthy (51-100).

When the factory was inactive, the average AQI in the higher level was estimated to be $413.6 \mu \mathrm{g} / \mathrm{m}^{3}$ and the air pollution level was hazardous. The lowest AQI (less than $50 \mu \mathrm{g} / \mathrm{m}^{3}$ ) was estimated at Stations 2, 5, and 9 (Table 4). Maximum AQIs were estimated at Stations 4, 6, 7, and 8 and were equal to $225.4,141.6,123.3$, and $184.2 \mu \mathrm{g} / \mathrm{m}^{3}$, respectively.

The AQI zoning map showed that the air quality was very healthy at Stations 2, 5, and 9 (outside the factory) and unhealthy and very hazardous at Stations 4 (60 to $80 \mathrm{~m}$ from the factory) and 1, respectively, at active factory times (Figure 8); therefore, the air quality was improved at greater distances from the factory. Finally, at a distance of 100 to $200 \mathrm{~m}$, the air quality returned to normal levels.

\section{Discussion}

The results of this paper showed that the average PM concentration was much lower at inactive times than at active times of the Nasr factory; hence, Nasr Kashan Concrete Factory played an important role in the emissions

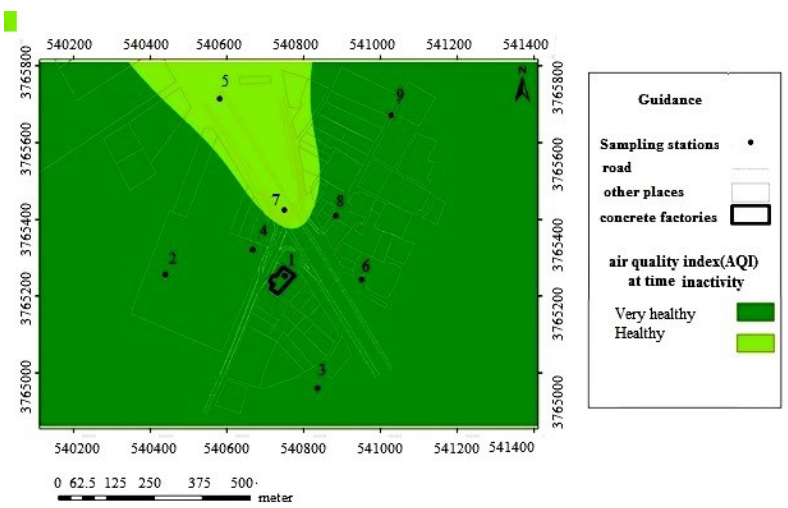

Figure 8. Zoning map of AQI of PM at inactive times of the Nasr factory in the studied area

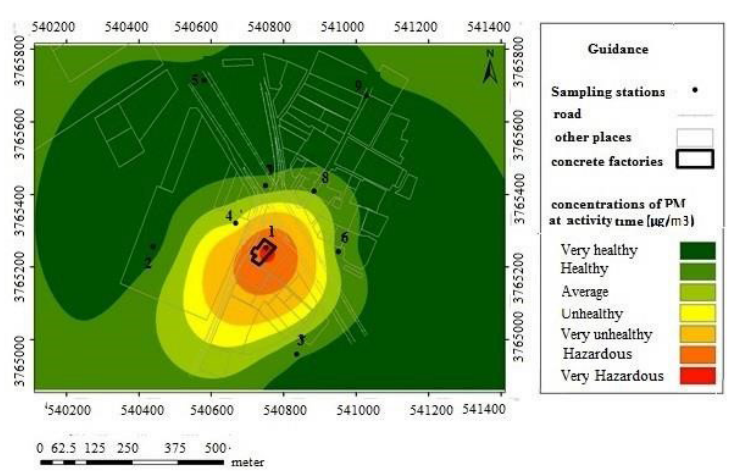

Figure 9. Zoning map of air quality index of particulate matter at active times of the Nasr factory in the studied area. 
Table 4. Comparison of air quality indexes at active and inactive factory times $\left(\mu \mathrm{g} / \mathrm{m}^{3}\right)$

\begin{tabular}{lcccccc}
\hline \multirow{2}{*}{ Station } & \multicolumn{3}{c}{ AQI at time activity } & \multicolumn{3}{c}{ AQI at time inactivity } \\
\cline { 2 - 7 } & Maximum & Minimum & Average & Maximum & Minimum & Average \\
\hline 1 & 634 & 249.8 & 413.6 & 59.3 & 18.5 & 43 \\
2 & 51 & 24.1 & 34.4 & 34.3 & 13.9 & 21.1 \\
3 & 76.2 & 35.2 & 61.4 & 53.5 & 14.8 & 26.1 \\
4 & 225.4 & 107.4 & 151.8 & 51.5 & 13.9 & 33.4 \\
5 & 55.4 & 26.9 & 41.6 & 71.6 & 35.2 & 53.8 \\
6 & 141.6 & 51 & 86.5 & 56.4 & 14.8 & 36.1 \\
7 & 123.3 & 41.7 & 71.3 & 70.1 & 23.1 & 55.5 \\
9 & 184.2 & 61.3 & 91.6 & 59.8 & 16.7 & 41.8 \\
\hline
\end{tabular}

of particulate matters and air pollution in the studied area, such that the particulate matter concentration increased near and inside the studied factory, and the AQI reached the hazardous level. This pollution can pose a serious threat to workers and experts working in the factory. Particulate matter is the main factor of many respiratory diseases occurring among citizens in their places of residence and work. A study conducted in 51 countries found that when the air pollution index increases up to 60 ppm, incidence of coronary heart disease also increases up to $10 \%$ (12). Particulate matter 2.5 (PM2.5) are wellknown criteria pollutants that pose a risk to public health (9-11). Studies have shown that ambient air pollution is associated with increased risk of respiratory disease and cardiovascular disease (CVD) mortality (13).

In addition, increasing concentrations of particulate matters and secondary hydrocarbons and ozone cause significant increases in rates of ventricular heart and blood pressure and complications in older people $(14,15)$. Longterm increases in these pollutants with ozone cause heart attack and fatal cardiovascular disease $(16,17)$. Increase in the amount of particulate matter (10 micrograms per cubic meter) increases these attacks by $2 \%$ percent (7). In this study, the average concentration of particulate matter at inactive times of Nasr factory $(22 / 8-64 / 2 \mu \mathrm{g} /$ $\mathrm{m}^{3}$ ) was lower than the recommended EPA standard (155$254 \mu \mathrm{g} / \mathrm{m}^{3}$ ), but at times of activity of Nasr factory, the average concentration of PM was higher than the value recommended by WHO guidelines $(5,18)$. In the same study by Jafarzadeh Haghighi et al (19) on the national Iranian steel industry, the average TSP concentration in sampled air was higher than the standard value and the standard of Iran $\left(\mathrm{EPA}=250 \mu \mathrm{m} / \mathrm{m}^{3}\right)$. The annual average of the samples was 649 micrograms per cubic meter. So this study showed that environmental factors affect the dispersion and distribution of air pollution. Hence, the height of the Nasr Kashan Concrete factory wall may be an important factor in reducing the dispersion of pollution. The emission height of PM10 (mixing tank cement, sand, and water) is $3 \mathrm{~m}$ when the factory is active, but the height of the factory wall is $230 \mathrm{~cm}$. Therefore, raising the height of the factory walls to higher than $3 \mathrm{~m}$ will make a significant reduction in the amount of particles dispersed. An important subject is that concrete companies are easy to move and settle; therefore, when large civil projects are in progress in an area, concrete companies are easily established and increase PM pollution in that area, especially in large cities. Thus, it is recommended that concrete factories be established outside residential areas and the establishment of this type of factory in city centers and crowded places be prevented, especially at the time of the large construction operations.

Muindi et al (20) stated that outside sources have an impact on inside sources and levels, especially in areas closest to the studied area. Since the Nasr factory is located at the intersection of two major highways, it seems the transit of vehicles causes dust and dispersion of particulate matter in the streets and increases the volume of PM in the studied area, such as Stations 4, 6, and 7.

\section{Conclusion}

In this study, the AQI zoning map showed that the activity of the factory increased the PM10 concentration in the studied area with the highest levels found at stations inside the factory; however, PM10 levels decreased at distances of $200 \mathrm{~m}$ from the factory. It can be concluded that the Nasr Kashan Concrete factory causes PM pollution in the studied area.

The results showed that all peaks of the AQI were less than 60 , falling into the good and very good categories of air quality at the inactive times of the factory. Thus, the AQI was in the range of very healthy $(0-50)$ to healthy (51-100). When the factory was active, AQIs were in the range of 24.1 to $634 \mu \mathrm{m} / \mathrm{m}^{3}$, falling into the good and very hazardous categories. It seems that the index values were related to the distance of the stations from the factory. Based on the results of this study, it is recommended that the factory walls be raised as high as possible and fastgrowing trees be cultivated near the factory. Furthermore, materials must be wet before production is started. Since lowlands are the best places for factories, it is proposed that the concrete plant be established outside of residential 
areas where people are most exposed to the greatest amounts of pollution caused by these activities.

\section{Summary of recommendations:}

- Transfer concrete factory to outside the city to reduce emissions of PM from the factory;

- Minimize particulate emissions to surrounding areas by growing plants and trees such as spruce and constructing walls as high as possible around the concrete plant to act as windbreaks;

- Conduct further studies in seasons other than autumn, when this research was conducted.

\section{Acknowledgments}

This research is derived from a Master's thesis. The authors express their appreciation to Iran's Environmental Protection Organization and the Nasr Beton factory for their cooperation in providing data.

\section{Competing interests}

The authors have no competing interests to declare.

\section{Ethical issues}

Ethical issues have been completely observed by the authors

\section{Authors' contributions}

All authors participated in data acquisition, analysis, and interpretation. All authors critically reviewed, refined, and approved the manuscript.

\section{References}

1. Mitran G, Ilie S. Study of particulate matters pollution related with meteorological factors for a city from SouthCentral of Romania. European Journal of Sustainable Development 2014; 3(4): 17-28. doi: 10.14207/ejsd.2014. v3n4p17.

2. Omidi Y, Goudarzi G, Heidari AM, Daryanoosh SM. Health impact assessment of short-term exposure to $\mathrm{NO}_{2}$ in Kermanshah, Iran using Air Q model. Environmental Health Engineering and Management Journal 2016; 3(2): 91-7. doi: 10.15171/ehemj.2016.06.

3. Ali K, Budhavant KB, Safai PD, Rao PS. Seasonal factors influencing in chemical composition of total suspended particles at Pune, India. Sci Total Environ 2012; 414: 257 67. doi: 10.1016/j.scitotenv.2011.09.011.

4. Colls J. Air Pollution (Clays Library of Health \& the Environment). 2nd ed. London: Spon Press; 2002.

5. EPA. Air Quality Index (AQI): Office of Air Quality Planning and Standards (OAQPS). USEPA, USA: 2006. http://www.epa.gov/airs/criteria.html.

6. Sharma M, Maloo, S. Assessment of ambient air $\mathrm{PM}_{10}$ and $\mathrm{PM}_{25}$ and characterization of $\mathrm{PM}_{10}$ in the city of Kanpur: India. Atmos Environ (1994) 2005; 39(33): 6015-26. doi: 10.1016/j.atmosenv.2005.04.041.
7. Naddafi K. Nabizadeh R, Nazmara SH, Nurmordadi HA, Mohamadi Moghadam F. Investigation of TSP and PM10 and describing the air quality based on AQI index in the air of central areas in Tehran in 2007-2006. Health System Researches 2009; 6 (4): 657-65. [In Persian].

8. Naddafi K, Ehrampoush $M$, JafariV, Nabizadeh $R$, Younesian $\mathrm{M}$. Investigation of total particulate matters and compounds of its constituent materials in the central region of Yazd. J Shahisadoghi University of Medical Sciences and Health Services of Yazd 2007; 6(4): 21-5. [In Persian].

9. NIOSH. NIOSH Health Hazard Evaluation Report No. 930775. http://www.cdc.gov/niosh/hhe/reports/pdfs/19930775-2398.pdf.

10. Hoseini G, Teymouri P, Shahmoradi B, Maleki A. Determination of the concentration and composition of PM10 during the Middle Eastern dust storms in Sanandaj, Iran. J Res Health Sci. 2015; 15(3): 182-188.

11. US EPA. Air Quality Index (AQI) - A Guide to Air Quality and Your Health. EPA; 2011. http://www.airnow.gov/index. $\mathrm{cfm}$ ?action=aqibasics.aqi.

12. Ahmadi H, Ahmadi T, Shahmoradi B, MohammadiSh, Kohzadi Sh. The effect of climatic parameters on air pollution in Sanandaj, Iran. Journal of Advances in Environmental Health Research 2015; 3: 49-61.

13. Balluz L, Wen XJ, Town M, Shire JD, Qualter J, Mokdad A. Ischemic heart disease and ambient air pollution of particulate matter 2.5 in 51 counties in the U.S. Public Health Rep 2007; 122(5): 626-33. doi: $10.1177 / 003335490712200510$.

14. Dockery DW, Schwartz J, Spengler JD. Air pollution and daily mortality: associations with particulates and acid aerosols. Environ Res 1992; 59(2): 362-73. doi: 10.1016/ S0013-9351(05)80042-8

15. Thurston GD, Ito K, Kinney PL, Lippmann M. A multi-year study of air pollution and respiratory hospital admissions in three New York state metropolitan areas: result for 1988 to 1989 summers. J Expo Anal Environ Epidemiol 1992; 2(4): 429-50.

16. Prioleau WH. Fine particulate air pollution and cardiovascular disease. J S C Med Assoc 2009; 105(6): 2023.

17. Chen LH, Knutsen SF, Shavlik D, Beeson WL, Petersen F, Ghamsary M, et al. The association between fatal coronary heart disease and ambient particulate air pollution: Are females at greater risk? Environ Health Perspect 2005; 113(12): 1723-9. doi: 10.1289/ehp.8190.

18. EPA. Air Quality Index Air Quality Index [A Guide to Your Health Air and Radiation]. EPA; 2003. http://www.epa.gov.

19. Rafiei M, Gadgil AS, Ghole VS, Jaafarzadeh N, Gore SD, Aberomand $\mathrm{M}$, et al. Investigation of respirable particulate matter pollutants on air-breathing zone workers in the Beam Rolling Mills Factory (Iran National Steel Industrial Group), Ahvaz, Iran. Indian J Occup Environ Med 2008; 12(2): 71-5. doi: 10.4103/0019-5278.43264.

20. Muindi K, Kimani-Murage E, Egondi T, Rocklov J, Ng N. Household air pollution: sources and exposure levels to fine particulate matter in Nairobi slums. Toxics 2016; 4(3): 12. doi: $10.3390 /$ toxics 4030012 